\title{
FIXAÇÃO BIOLÓGICA DE NITROGÊNIO E TEORES FOLIARES DE NUTRIENTES NA SOJA EM FUNÇ̃̃O DE DOSES DE MOLIBDÊNIO E GESSO AGRÍCOLA ${ }^{1}$
}

\author{
Biological nitrogen fixation and leaf nutrient concentration on soybean as a \\ function of molybdenum and gypsum levels ${ }^{1}$
}

\author{
Evandro Gelain ${ }^{2}$, Edgard Jardim Rosa Junior ${ }^{3}$, Fábio Martins Mercante ${ }^{4}$, \\ Danilo Gomes Fortes ${ }^{3}$, Fábio Régis de $\mathrm{Souza}^{3}$, Yara Brito Chaim Jardim Rosa ${ }^{3}$
}

\begin{abstract}
RESUMO
A competitividade econômica da soja brasileira no mercado mundial se deve, em grande parte, aos benefícios da fixação biológica do nitrogênio na cultura. $\mathrm{O}$ trabalho foi conduzido a campo, sob sistema plantio direto, em condição de sequeiro, no Município de Maracaju-MS, com o objetivo de avaliar a nodulação, o crescimento, nutrição mineral e produtividade de grãos da soja submetida a diferentes doses de gesso agrícola e molibdênio. Foi utilizado o delineamento experimental de blocos ao acaso, com cinco repetições e esquema de parcelas subdivididas, sendo as parcelas representadas por quatro doses de gesso agrícola $(0,1.000,2.000$ e $\left.3.000 \mathrm{~kg} \mathrm{ha}^{-1}\right)$ e as subparcelas, por quatro doses de molibdênio $\left(0,20,40 \mathrm{e} 60 \mathrm{~g} \mathrm{ha}^{-1}\right)$. Não houve efeito da interação gesso x Mo sobre a produtividade da soja. $\mathrm{O}$ gesso agrícola não influencia no teor foliar de $\mathrm{N}$ e na produtividade. O Mo proporciona incrementos na produtividade e no teor de proteínas dos grãos.
\end{abstract}

Termos para indexação: Glycine max, Bradyrhizobium japonicum, nutrição de planta.

\section{ABSTRACT}

The economic competitiveness of Brazilian soybeans on the world market occurs, in large part, due to the benefits of biological nitrogen fixation in this crop. The field experiment was carried out in Maracaju, Mato Grosso do Sul State, Brazil, under no-tillage system, in rainfed condition. The aim was to evaluate nodulation, growth, mineral nutrition and grain yield of soybeans under different doses of gypsum and molybdenum. The experimental design used was a randomized block with five replicates and arranged in a split-plot squeme, with the plot represented by four doses of gypsum $\left(0,1.000,2.000\right.$ and $\left.3.000 \mathrm{~kg} \mathrm{ha}^{-1}\right)$ and the subplots by four doses of molybdenum $\left(0,20,40\right.$ and $\left.60 \mathrm{~g} \mathrm{ha}^{-1}\right)$. There were no interaction effects of Mo x gypsum for grain yield. Gypsum has no influence in the $\mathrm{N}$ leaf content and grain yield. Mo increases grain yield and protein levels in the grain.

Index terms: Glycine max, Bradyrhizobium japonicum, plant nutrition.

(Recebido em 10 de março de 2010 e aprovado em 14 de julho de 2010)

\section{INTRODUÇÃO}

A soja [Glycine $\max ($ L.) Merrill] requer grandes quantidades de nitrogênio, dado ao elevado teor de proteína nos seus grãos. Em cultivares altamente produtivos, já se observou que a fixação biológica de nitrogênio (FBN) fornece até $94 \%$ do $\mathrm{N}$ requerido pela cultura (Hungria et al., 2006) e que, na ausência da simbiose, os custos com adubação nitrogenada se elevam, resultando em perda de competitividade da soja (Hungria et al., 2007). Contudo, fatores edáficos como acidez do solo e deficiência de molibdênio (Mo), cobalto $(\mathrm{Co})$ e fósforo $(\mathrm{P})$, além de outros nutrientes, podem afetar a FBN na soja (Vargas \& Hungria, 1997).
$\mathrm{O}$ Mo no solo tem a forma aniônica $\left(\mathrm{HMoO}_{4}^{-} \mathrm{e}\right.$ $\mathrm{MoO}_{4}^{-2}$ ), podendo ser adsorvido de maneira similar ao que acontece com o sulfato e fosfato. A absorção desse nutriente pode ser estimulada pelo ânion fosfato, no entanto, o sulfato a inibe, por competição (Malavolta et al., 1997). O Mo faz parte da molécula da nitrogenase, que catalisa a redução do $\mathrm{N}_{2}$ à forma de amônia. A nitrogenase consiste em uma ferro-proteína (Fe-proteína) e em uma molibdênio-ferro-proteína (MoFe-proteína); a primeira funciona como doadora de elétrons para a segunda, em um processo dependente de hidrólise de MgATP (Teixeira et al., 1998). O Mo também faz parte da enzima redutase de nitrato, que catalisa a redução de nitrato a nitrito (Malavolta, 2006). As quantidades de Mo requeridas pelas

\footnotetext{
'Extraído da dissertação de mestrado apresentada pelo primeiro autor à Universidade Federal da Grande Dourados/UFGD - MS

2Universidade Federal da Grande Dourados/UFGD - Faculdade de Ciências Agrárias/FCA - Rodovia Dourados - Itahum - km 12 - Cx. P. 533 79804-970 - Dourados, MS - evandro_gelain@hotmail.com

3Universidade Federal da Grande Dourados/UFGD - Faculdade de Ciências Agrárias/FCA - Dourados, MS

${ }^{4}$ Empresa Brasileira de Pesquisa Agropecuária/Embrapa - Agropecuária Oeste - Dourados, MS
} 
plantas são pequenas e a aplicação via semente constitui-se em uma das formas mais práticas e eficazes de adubação molíbdica (Campo \& Lantmann, 1998). As principais fontes de Mo são o molibdato de sódio e de amônio, o ácido molíbdico e o trióxido de molibdênio (Albino \& Campo, 2001). Efeitos de toxicidade das fontes de Mo na sobrevivência de estirpes de Bradyrhizobium sp. são conhecidos e comentados (Albino \& Campo, 2001; Campo et al., 2009), e são atribuídos ao efeito osmótico negativo dos sais usados como fontes de Mo (Campo et al., 2009). O tratamento de sementes (TS) com Mo tem proporcionado incrementos de produtividade (Albino \& Campo, 2001), mas as respostas da soja à adubação com Mo têm sido variáveis, ocorrendo incrementos significativos na produtividade de grãos (Sfredo et al., 1997) ou ausência de resposta (Pessoa et al., 1999; Souza et al., 2009). Contudo, tem sido observado que mesmo sem ocorrência de deficiência de Mo, o cultivo intensivo, sem aplicação do nutriente, leva ao empobrecimento do solo e, consequentemente, a resposta à sua utilização (Hungria et al., 2007).

Outro fator limitante da produtividade de grãos da soja é a elevada acidez dos solos, como ocorre, de modo geral, nos cerrados, em superfície e em subsuperfície. A incorporação profunda de calcário para corrigir essa acidez nem sempre é viável, já que esse corretivo apresenta baixa mobilidade no solo (Sousa \& Lobato, 2002). Nessas condições, o gesso agrícola tem apresentado resultados satisfatórios como melhorador do ambiente radicular em profundidade, proporcionado pelo aumento dos teores de $\mathrm{Ca}$ e diminuição dos teores de Al em subsuperfície (Caires et al., 2003). Em geral, solos sob exploração há muitos anos, com uso de fertilizantes desprovidos de enxofre (S), podem apresentar baixa disponibilidade desse nutriente. Isso pode resultar em sintomas de deficiência nas culturas, acarretando queda de produtividade, principalmente em solos pobres em $\mathrm{S}$ e com baixos teores de matéria orgânica. Considerando que a soja é uma das culturas que mais exporta $\mathrm{S}$, com $5 \mathrm{~kg}$ por tonelada de grãos (Empresa Brasileira de Pesquisa Agropecuária - Embrapa, 2008), resultando em exportação total de cerca de 170 mil toneladas de S por safra, o gesso agrícola pode, portanto, aumentar a produtividade de culturas como a soja, pelo fornecimento de S (Mascarenhas et al., 1986).

Em solos onde se utiliza o gesso como corretivo de subsuperfície, há fornecimento de quantidades elevadas de $\mathrm{S}$ na forma de sulfato, podendo ocorrer algum efeito negativo na disponibilidade de Mo e, dessa forma, causar prejuízos à FBN, tornando-se necessária a utilização de maiores doses desse micronutriente.

Objetivou-se, com este trabalho, estudar os efeitos da adição de gesso agrícola e do molibdênio na nodulação, no crescimento, nutrição mineral, teor foliar de nutrientes e produtividade de grãos da cultura da soja.

\section{MATERIAL E MÉTODOS}

O trabalho foi conduzido na Fazenda Salgador, Município de Maracaju - MS, localizada nas coordenadas geográficas de $21^{\circ} 38^{\prime} 03^{\prime}$ ' S e $55^{\circ} 05^{\prime} 55^{\prime}$ ' $\mathrm{W}$, à uma altitude de $372 \mathrm{~m}$, entre novembro de 2007 e abril de 2008. O clima da região é tropical úmido, com chuvas no verão e com seca no inverno, classificado como Aw, segundo a classificação de Köppen (Secretaria de Planejamento e Coordenação Geral - Seplan, 1990), com precipitação média anual de 1500 a $1700 \mathrm{~mm}$

O estudo foi desenvolvido em sistema de semeadura direta, em condições de sequeiro, após 30 anos de exploração com pastagem (Brachiaria brizantha Stapf), em Latossolo Vermelho Distroférrico, de textura argilosa (330 $\mathrm{g} \mathrm{kg}^{-1}$ de areia; $130 \mathrm{~g} \mathrm{~kg}^{-1}$ de silte; $540 \mathrm{~g} \mathrm{~kg}^{-1}$ de argila). Os atributos químicos do solo empregado são apresentados na Tabela 1 .

A cultivar de soja utilizada foi a BRS Charrua RR, semeada com densidade de 25 sementes por metro linear e espaçamento de $0,45 \mathrm{~m}$ entre linhas. Aos 10 dias após a emergência da cultura, foi realizado o desbaste, deixandose 15 plantas por metro linear. O delineamento estatístico foi blocos casualizados, esquema experimental parcelas subdivididas, com cinco repetições. Nas parcelas, foram aplicadas quatro doses de gesso agrícola em superfície $\left(0,1.000,2.000\right.$ e $\left.3.000 \mathrm{~kg} \mathrm{ha}^{-1}\right)$ e, nas subparcelas, quatro

Tabela 1 - Atributos químicos do solo antes da instalação do experimento, determinados em duas profundidades.

\begin{tabular}{|c|c|c|c|c|c|c|c|c|c|c|c|c|}
\hline Prof. & $\mathrm{pH}^{*}$ & M.O. & $\mathrm{P}$ & $\mathrm{S}$ & $\mathrm{K}$ & $\mathrm{Ca}$ & $\mathrm{Mg}$ & $\mathrm{Al}$ & $\mathrm{H}+\mathrm{Al}$ & CTC & $\mathrm{V}$ & $\mathrm{m}$ \\
\hline & & $\mathrm{g} \mathrm{dm}^{-3}$ & \multicolumn{2}{|c|}{$--\mathrm{mg} \mathrm{dm}^{-3}--$} & \multicolumn{6}{|c|}{ 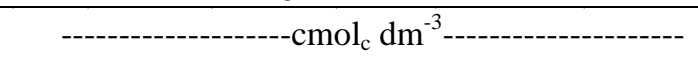 } & \multicolumn{2}{|c|}{$----\%$} \\
\hline $0-20 \mathrm{~cm}$ & 4,6 & 43,9 & 4,6 & 7,6 & 0,30 & 2,58 & 1,54 & 0,48 & 6,60 & 11,22 & 40 & 9 \\
\hline $20-40 \mathrm{~cm}$ & 4,4 & 20,3 & 0,8 & 5,3 & 0,09 & 1,44 & 0,58 & 1,41 & 9,44 & 11,55 & 18 & 40 \\
\hline
\end{tabular}

$* \mathrm{pH} \mathrm{em} \mathrm{CaCl}_{2}$. 
doses de Mo (0, 20, 40 e $60 \mathrm{~g} \mathrm{ha}^{-1}$ de Mo via tratamento de sementes - TS), utilizando-se como fonte o molibdato de sódio ( $39 \%$ de Mo). As áreas totais das parcelas e subparcelas foram, respectivamente, de 120 e $30 \mathrm{~m}^{2}$, e as áreas úteis de 99 e $16,5 \mathrm{~m}^{2}$, respectivamente. Inicialmente, realizou-se a dessecação da área, utilizando herbicida à base de glifosato, na dosagem de $1.440 \mathrm{~g} \mathrm{ha}^{-1}$ do equivalente ácido.

O gesso agrícola foi aplicado manualmente, em 17 de novembro de 2007, sem incorporação ao solo; além disso, realizou-se uma correção na área total do ensaio com: $180 \mathrm{~kg} \mathrm{ha}^{-1}$ de $\mathrm{P}_{2} \mathrm{O}_{5}$ (superfosfato triplo), $150 \mathrm{~kg} \mathrm{ha}^{-1}$ de $\mathrm{K}_{2} \mathrm{O}$ (cloreto de potássio), $4 \mathrm{~kg} \mathrm{ha}^{-1}$ de $\mathrm{Zn}$ (granulado a base de óxido de zinco moído) e 1,5 kg ha-1 de B (granulado à base de ulexita moída).

As sementes utilizadas no experimento foram tratadas manualmente, no dia da semeadura, com as doses de Mo e com 2,16 $\mathrm{g} \mathrm{ha}^{-1}$ de cobalto, fonte sulfato de cobalto. Logo após o tratamento com micronutrientes ( $\mathrm{Mo}+\mathrm{Co}$ ), foi realizada a inoculação das sementes com produto comercial turfoso, com concentração de $5 \times 10^{9}$ células de bactérias viáveis por grama de inoculante, contendo as estirpes SEMIA 5079 (CPAC 15) e SEMIA 5080 (CPAC 7) de Bradyrhizobium japonicum Jordan 1982, na dosagem de $300 \mathrm{~g}$ para $50 \mathrm{~kg}$ de sementes, o que equivale, aproximadamente, a 4.050 .000 de células de bactéria por semente de soja.

Aos 26 dias após a aplicação das doses de gesso, foi efetuada a semeadura mecânica da soja, utilizando-se uma adubação de semeadura com $352 \mathrm{~kg} \mathrm{ha}^{-1} \mathrm{da}$ formulação 00-25-25 (N-P-K) + 0,45\% Zn + 0,10\% B. O controle de plantas daninhas (folhas largas e estreitas) foi realizado por meio de três aplicações do herbicida à base de glifosato, utilizando-se a dose de $540 \mathrm{~g} \mathrm{ha}^{-1}$ do equivalente ácido, em pós-emergência da cultura e das plantas daninhas. Para o controle de lagartas, foram necessárias três aplicações de inseticidas, sendo utilizada, na primeira e na terceira, a mistura de profenofós + lufenurom nas doses de 150 e $15 \mathrm{~g} \mathrm{ha}^{-1}$, respectivamente; na segunda aplicação, foi utilizada a mistura de endossulfan + diflubenzurom, nas doses de 175 e de $12 \mathrm{~g} \mathrm{ha}^{-1}$, respectivamente. Para o controle de percevejos, foram realizadas duas aplicações de produto com princípio ativo metamidofós, na dose de $480 \mathrm{~g} \mathrm{ha}^{-1}$. Para o controle da ferrugem asiática e do complexo de doenças, foram utilizadas duas aplicações, nos estádios R2 (florescimento pleno) e R5.1 (início da formação dos grãos), de ciproconazol + azoxistrobina, nas doses de 24 e $60 \mathrm{~g} \mathrm{ha}^{-1}$, respectivamente.

Aos 40 dias após a emergência da soja (estádio $\mathrm{R} 1$ ), foram retiradas de 5 a 10 plantas de cada subparcela seguindo a metodologia preconizada pelo Protocolo... (2007). Essas amostras foram separadas em parte aérea e raízes. As raízes foram lavadas em água corrente e, depois da remoção do solo nelas aderido, os nódulos foram destacados das raízes e contados. Os nódulos e a parte aérea das plantas foram colocados para secar em estufa com circulação forçada de ar à temperatura de $60 \pm 5^{\circ} \mathrm{C}$ até atingir massa constante.

Por ocasião do florescimento pleno (estádio R2), foram coletados 20 trifólios, recém-maduros, sem pecíolo, por parcela. As folhas foram lavadas com água destilada e colocadas para secar em estufa com circulação forçada de ar, a uma temperatura de $60 \pm 5^{\circ} \mathrm{C}$, até atingir massa constante. A determinação do teor de nutrientes foliares foi realizada seguindo a metodologia proposta por Malavolta et al. (1997).

No estádio R5.5, foi realizada a leitura indireta do teor de clorofila das folhas de soja, utilizando-se o índice SPAD, obtido com clorofilômetro Minolta SPAD-502. A leitura foi realizada na última folha da soja, no folíolo central, sendo efetuadas dez leituras por subparcela. Os dados da leitura foram transformados em teor de clorofila $\left(\mathrm{mg} \mathrm{dm}^{-2}\right)$, utilizando-se a equação: $y=-0,152+0,0996 x$, proposta por Barnes et al. (1992).

A produtividade de grãos de soja foi avaliada pela colheita em três linhas, com quatro metros de comprimento, totalizando $5,4 \mathrm{~m}^{2}$ de área colhida por subparcela. $\mathrm{O}$ produto colhido foi trilhado mecanicamente, sendo determinadas a massa absoluta de grãos e a massa de cem grãos e, posteriormente, corrigido o conteúdo de umidade para $13 \%$. O teor $\mathrm{N}$ nos grãos foi determinado pelo método de Kjeldahl para quantificação de nitrogênio total (Malavolta et al., 1997). Para o cálculo da conversão de nitrogênio em proteína, foi utilizado o fator 6,25.

Os dados da precipitação pluvial, no período do experimento, estão demonstrados na Figura 1.

Os dados obtidos para cada característica avaliada foram submetidos à análise de variância pelo teste $\mathrm{F}$ a $5 \%$ de probabilidade e, quando houve diferenças significativas, foram ajustadas equações de regressão para se estudar os efeitos da aplicação do gesso e do Mo. Para os procedimentos estatísticos, utilizou-se o aplicativo computacional SAEG 9.1 (Universidade Federal de Viçosa - UFV, 2007).

\section{RESULTADOS E DISCUSSÃO}

Os valores médios obtidos no estudo são apresentados nas Tabelas 2 e 3.

Houve significância da doses de gesso $\mathrm{x}$ doses de Mo sobre os teores de $\mathrm{K}$ e de clorofila nas folhas da soja 


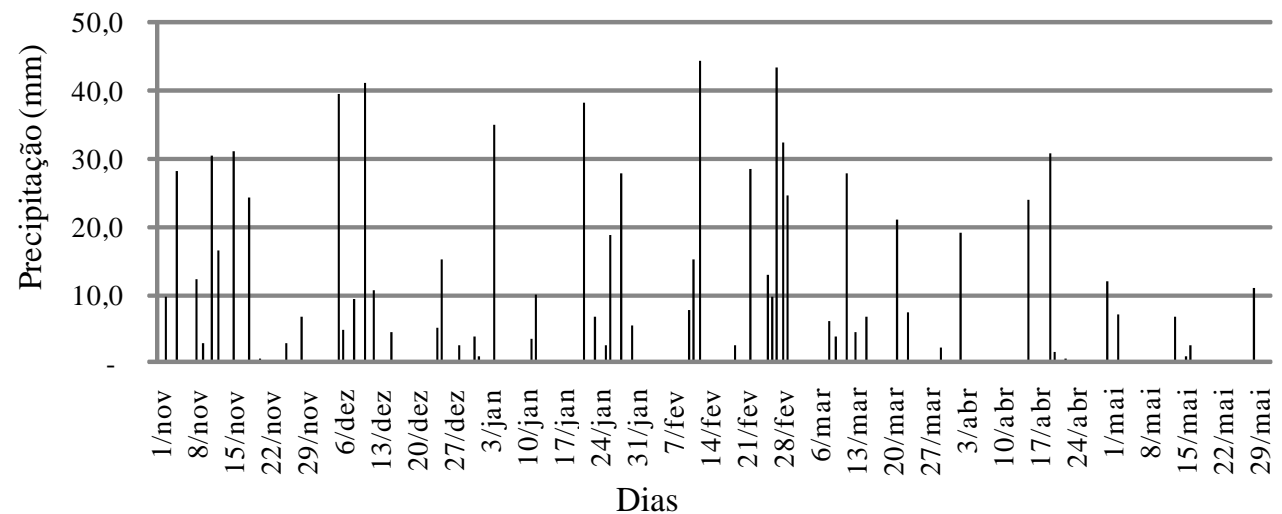

Figura 1 - Precipitação pluviométrica, diária, ocorrida no local do experimento, entre os meses de novembro de 2007 e abril de 2008.

Tabela 2 - Efeito das doses de gesso e Mo no índice SPAD de clorofila (SPAD), massa seca da parte aérea (MSPA), número de nódulos por planta (NN), massa seca de nódulos por planta (MSN), produtividade da soja (PROD), massa de cem grãos (MS100) e teor de proteínas dos grãos (PROT).

\begin{tabular}{|c|c|c|c|c|c|c|c|}
\hline Tratamento & SPAD & MSPA & $\mathrm{NN}$ & MSN & PROD & MS100 & PROT \\
\hline \multicolumn{8}{|l|}{$\operatorname{Mo}\left(\mathrm{g} \mathrm{ha}^{-1}\right)$} \\
\hline 0 & 3,54 & 3,1 & 42,9 & 209,3 & 1589 & 11,0 & 33,3 \\
\hline 20 & 4,10 & 3,9 & 41,3 & 220,7 & 2590 & 13,4 & 38,8 \\
\hline 40 & 4,11 & 3,9 & 36,0 & 190,4 & 2478 & 13,2 & 38,9 \\
\hline 60 & 4,08 & 3,8 & 35,3 & 200,2 & 2555 & 13,2 & 39,7 \\
\hline Efeito & $Q^{* *}$ & $\mathrm{RQ}^{*}$ & $\mathrm{~L}^{* *}$ & ns & $\mathrm{RQ}^{* *}$ & $\mathrm{RQ}^{* *}$ & $\mathrm{RQ}^{* *}$ \\
\hline $\mathrm{CV}(\%)$ & 3,4 & 21,9 & 21,8 & 22,7 & 10,7 & 3,3 & 5,1 \\
\hline \multicolumn{8}{|l|}{ Gesso $\left(\mathrm{t} \mathrm{ha}^{-1}\right)$} \\
\hline 0 & 4,05 & 3,7 & 38,5 & 203,4 & 2317 & 13,0 & 38,0 \\
\hline 1 & 3,94 & 3,5 & 39,7 & 208,9 & 2266 & 12,5 & 38,0 \\
\hline 2 & 3,92 & 4,2 & 43,1 & 220,6 & 2375 & 12,6 & 37,5 \\
\hline 3 & 3,91 & 3,5 & 36,4 & 198,2 & 2286 & 12,7 & 37,0 \\
\hline Efeito & $\mathrm{L}^{*}$ & ns & $Q^{*}$ & ns & ns & $\mathrm{RQ}^{*}$ & ns \\
\hline $\mathrm{CV}(\%)$ & 3,1 & 16,4 & 18,0 & 29,4 & 14,4 & 2,3 & 4,4 \\
\hline Médias & 3,95 & 3,7 & 39,2 & 206,5 & 2307 & 12,7 & 37,6 \\
\hline
\end{tabular}

L, Q, RQ: efeito linear, quadrático e raiz quadrada por regressão polinomial, respectivamente. *, ${ }^{* *}$ e ns: significativos a $\mathrm{p}<0,05 \mathrm{e}$ $\mathrm{p}<0,01$ e não-significativo, respectivamente.

( $\mathrm{p}<0,05)$; no restante das variáveis avaliadas, ocorreu somente efeito isolado dos tratamentos principais. A superfície de resposta do teor foliar de $\mathrm{K}$ indica que ele foi mais elevado (21,9 $\left.\mathrm{g} \mathrm{kg}^{-1}\right)$ quando se utilizaram $3.000 \mathrm{~kg} \mathrm{ha}^{-1}$ de gesso e $60 \mathrm{~g} \mathrm{ha}^{-1}$ de Mo. $\mathrm{O}$ teor foliar de $\mathrm{K}$ foi mais baixo $\left(17,4 \mathrm{~g} \mathrm{~kg}^{-1}\right)$ com $3.000 \mathrm{~kg} \mathrm{ha}^{-1}$ de gesso, sem a utilização do Mo (Figura 2A). Observou-se interação entre o gesso e o Mo, verificando-se que o aumento da dose de gesso, sem a aplicação de Mo, resultou na diminuição do teor foliar de
$\mathrm{K}$; no entanto, com o aumento da dose de gesso na presença da maior dose de Mo $\left(60 \mathrm{~g} \mathrm{ha}^{-1}\right)$, o teor foliar de $\mathrm{K}$ também foi aumentado.

$\mathrm{Na}$ superfície de resposta ajustada para o índice $\mathrm{SPAD}$, verifica-se que o maior teor de clorofila $\left(4,25 \mathrm{mg} \mathrm{dm}^{-2}\right)$ foi alcançado com a dose de $41 \mathrm{~g} \mathrm{ha}^{-1}$ de Mo, sem a utilização de gesso, e o menor teor de clorofila $\left(3,50 \mathrm{mg} \mathrm{dm}^{-2}\right)$ foi alcançado sem a utilização de Mo e com a maior dose de gesso $\left(3000 \mathrm{~kg} \mathrm{ha}^{-1}\right)$. Observou-se que a utilização de maior 
quantidade de gesso acarreta maior necessidade de Mo para se manter o mesmo teor de clorofila foliar (Figura 2B). Furlani Junior et al. (1996) concluíram que, em feijoeiro, houve excelentes correlações entre leitura indireta do teor de clorofila e os teores de $\mathrm{N}$ nas folhas. Partindo-se desse pressuposto, pode-se concluir que os teores de $\mathrm{N}$ nas folhas, nesse estádio mais avançado da cultura, também seriam influenciados pela interação gesso x Mo. Como o potencial produtivo da soja foi afetado pela ocorrência de veranicos no decorrer do ciclo da cultura (Figura 1), os efeitos da interação gesso x Mo não ocorreram na produtividade, que foi nivelada em patamares abaixo da média da região; entretanto, nas subparcelas em que não se utilizou o Mo, era perceptível um gradiente de maior amarelecimento nas folhas, conforme se aumentavam as doses de gesso. Pode-se então sugerir que, quando se utiliza o gesso agrícola, seria indispensável a utilização do Mo.

Tabela 3 - Efeito das doses de gesso e Mo nos teores de nutrientes em folhas coletadas no estádio R2.

\begin{tabular}{lcccccccccc}
\hline \multicolumn{1}{c}{ Tratamento } & $\mathrm{N}$ & $\mathrm{P}$ & $\mathrm{K}$ & $\mathrm{Ca}$ & $\mathrm{Mg}$ & $\mathrm{S}$ & $\mathrm{Zn}$ & $\mathrm{Fe}$ & $\mathrm{Mn}$ & $\mathrm{Cu}$ \\
\hline Mo $\left(\mathrm{g} \mathrm{ha}^{-1}\right)$ & & & & & & & & & & \\
0 & 37,6 & 3,6 & 19,1 & 7,9 & 3,4 & 3,0 & 52,9 & 194 & 232 & 9,3 \\
20 & 39,9 & 3,5 & 19,4 & 6,7 & 2,9 & 3,2 & 45,8 & 162 & 206 & 9,8 \\
40 & 39,8 & 3,5 & 20,3 & 7,4 & 3,0 & 3,0 & 42,6 & 203 & 188 & 9,6 \\
60 & 39,8 & 3,4 & 20,1 & 6,8 & 2,9 & 2,8 & 46,5 & 196 & 195 & 10,0 \\
Efeito & $\mathrm{RQ}^{* *}$ & $\mathrm{~ns}$ & $\mathrm{~L}^{*}$ & $\mathrm{RQ}^{*}$ & $\mathrm{RQ}^{*}$ & $\mathrm{Q}^{*}$ & $\mathrm{Q}^{* *}$ & $\mathrm{~ns}$ & $\mathrm{Q}^{*}$ & $\mathrm{~L}^{*}$ \\
$\mathrm{CV}(\%)$ & 4,9 & 16,3 & 10,7 & 14,2 & 12,2 & 10,6 & 11,3 & 28,5 & 14,7 & 8,0 \\
\hline Gesso $\left(\mathrm{t} \mathrm{ha}^{-1}\right)$ & & & & & & & & & & \\
0 & 39,5 & 3,6 & 19,6 & 6,9 & 3,2 & 2,9 & 46,3 & 191 & 204 & 9,7 \\
1 & 38,6 & 3,5 & 20,1 & 7,6 & 3,2 & 3,0 & 47,7 & 188 & 195 & 9,6 \\
2 & 39,7 & 3,4 & 19,4 & 7,1 & 2,9 & 3,1 & 47,1 & 181 & 216 & 9,9 \\
3 & 39,3 & 3,3 & 19,7 & 7,3 & 2,9 & 3,0 & 46,7 & 195 & 205 & 9,4 \\
Efeito & $\mathrm{ns}$ & $\mathrm{ns}$ & $\mathrm{ns}$ & $\mathrm{ns}$ & $\mathrm{L}^{*}$ & $\mathrm{Q}^{* *}$ & $\mathrm{~ns}$ & $\mathrm{~ns}$ & $\mathrm{~ns}$ & $\mathrm{Ns}$ \\
$\mathrm{CV}(\%)$ & 5,9 & 18,6 & 9,4 & 15,4 & 12,5 & 7,0 & 11,2 & 28,8 & 17,8 & 11,5 \\
\hline Médias & 39,3 & 3,47 & 19,7 & 7,2 & 3,1 & 3,0 & 47,0 & 189 & 205 & 9,6 \\
\hline
\end{tabular}

L, Q, RQ: efeito linear, quadrático e raiz quadrada por regressão polinomial, respectivamente. *, ** e ns: significativos a p $<0,05 \mathrm{e}$ $\mathrm{p}<0,01$ e não-significativo, respectivamente.
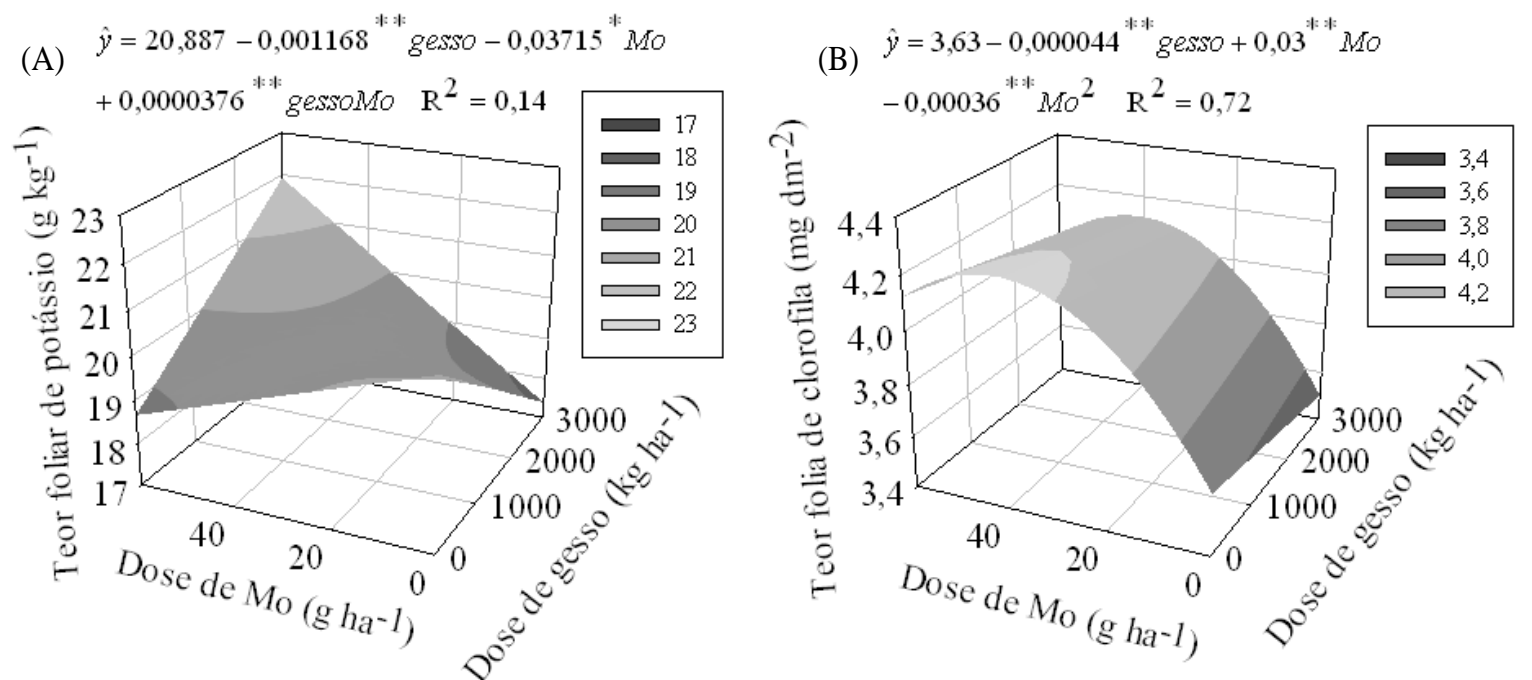

Figura 2 - Superfície de resposta para os teores de potássio (A) e de clorofila (B) em folhas de soja em função de doses de gesso agrícola e de Mo. Maracaju (MS). UFGD, 2009. 
A aplicação de Mo interferiu $(\mathrm{p}<0,05)$ no número de nódulos por planta, na matéria seca de parte aérea, na massa de cem grãos, no teor de proteínas, na produtividade de grãos e nos teores foliares de N, S, Ca, Mg, Cu, Mn e Zn (Figuras 3 e 4).

O número de nódulos das plantas de soja foi diminuído em $23 \%$ quando se utilizou $60 \mathrm{~g} \mathrm{ha}^{-1}$ de Mo (Figura 3A). Dados semelhantes foram obtidos por Albino \& Campo (2001), ao avaliarem diferentes fontes de Mo, na dose de $20 \mathrm{~g} \mathrm{ha}^{-1}$ via TS; observaram que o molibdato de sódio promoveu redução de $40 \%$ no número de nódulos radiculares. A redução do número de nódulos tem sido atribuída à composição salina dos produtos que fornecem o Mo (Campo et al., 2009). Apesar da adição de Mo ter promovido uma redução no número de nódulos das plantas no presente estudo, o menor número obtido (34 nódulos por planta) ainda foi superior aos valores indicativos de uma boa nodulação para a cultura, que variam de 15 a 30 nódulos, segundo Hungria et al. (2007).
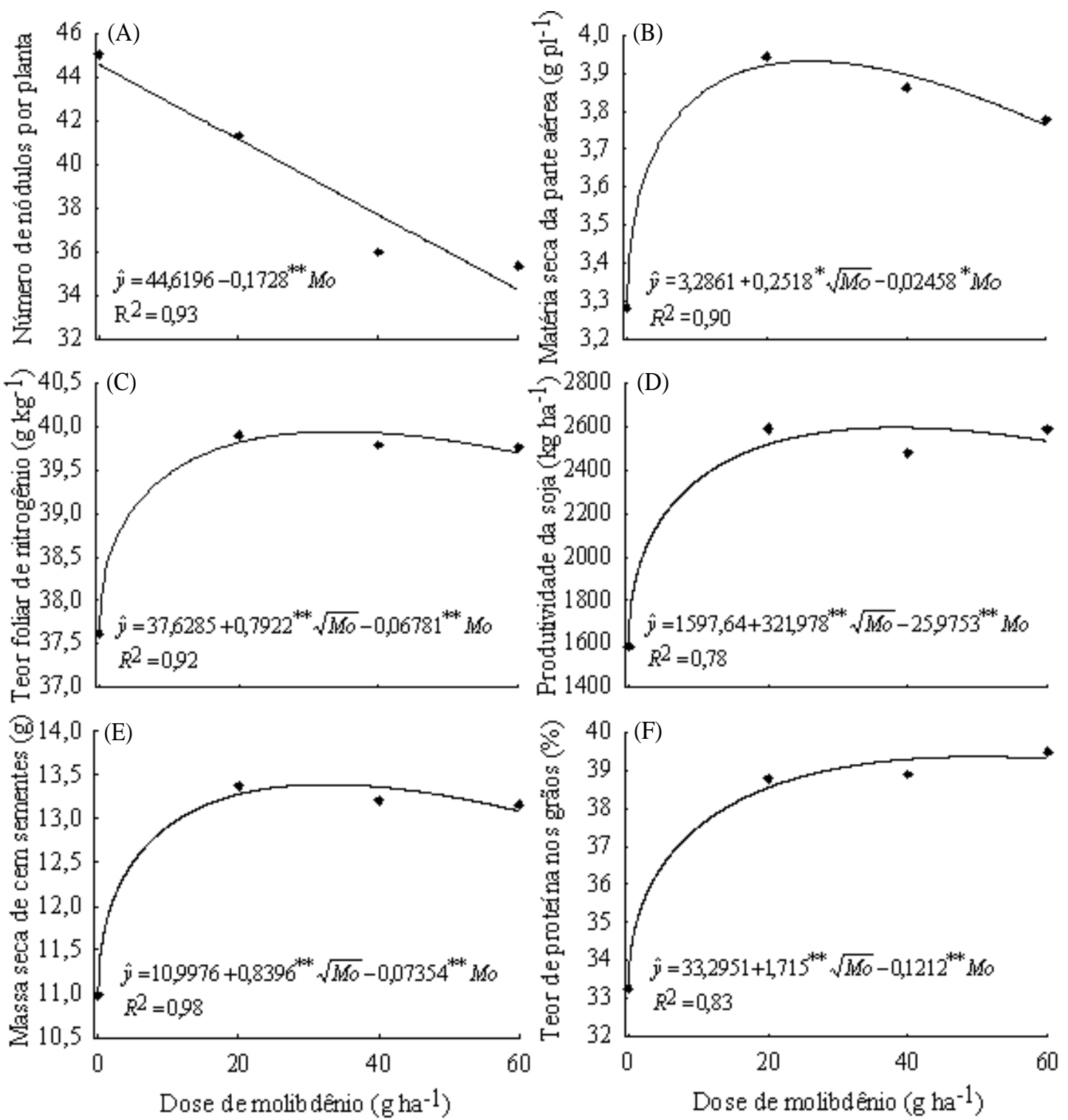

Figura 3 - Efeito das doses de molibdênio no número de nódulos por planta (A), na matéria seca de parte aérea (B), no teor foliar de nitrogênio (C), na produtividade da soja (D), na massa de cem grãos (E) e no teor de proteínas nos grãos (F). Maracaju (MS). UFGD, 2009. 
Com relação à matéria seca da parte aérea da soja, foi observado que a utilização de Mo proporcionou aumentos de até $20 \%$ com a adição de $26 \mathrm{~g} \mathrm{ha}^{-1}$ desse micronutriente (Figura 3B). O aumento da matéria seca ocorreu, provavelmente, devido à maior eficiência da $\mathrm{FBN}$, que teria proporcionado maior oferta de $\mathrm{N}$ fixado e, consequentemente maior crescimento vegetativo das plantas (Malavolta, 2006).

A aplicação de Mo (dose de $34 \mathrm{~g} \mathrm{ha}^{-1}$ ) aumentou o teor de $\mathrm{N}$ foliar em $6 \%$ em relação ao tratamento sem aplicação de Mo (Figura 3C). Esse resultado corrobora com as observações de Campo \& Lantmann (1998), em cinco diferentes solos do Estado do Paraná, onde os autores verificaram que, em três solos, ocorreram ganhos na nutrição de $\mathrm{N}$ na cultura da soja, quando se utilizou Mo. Tanaka et al. (1993), por sua vez, destacaram, em seus estudos, que, apesar da utilização de $20 \mathrm{~g} \mathrm{ha}^{-1}$ de Mo não ter alterado os teores foliares de $\mathrm{N}$, evidenciaram, via maior produtividade de grãos, que o $\mathrm{N}$ total absorvido foi maior do que onde não se utilizou o Mo; verificou-se ainda que o Mo adicionado na semente melhorou a eficiência da FBN e aumentou a absorção de $\mathrm{N}$ pela soja, já que não ocorreu diferença na massa seca de nódulos. Em estudos recentes, Campo et al. (2009) demonstraram que a utilização de sementes enriquecidas com Mo também podem suprir
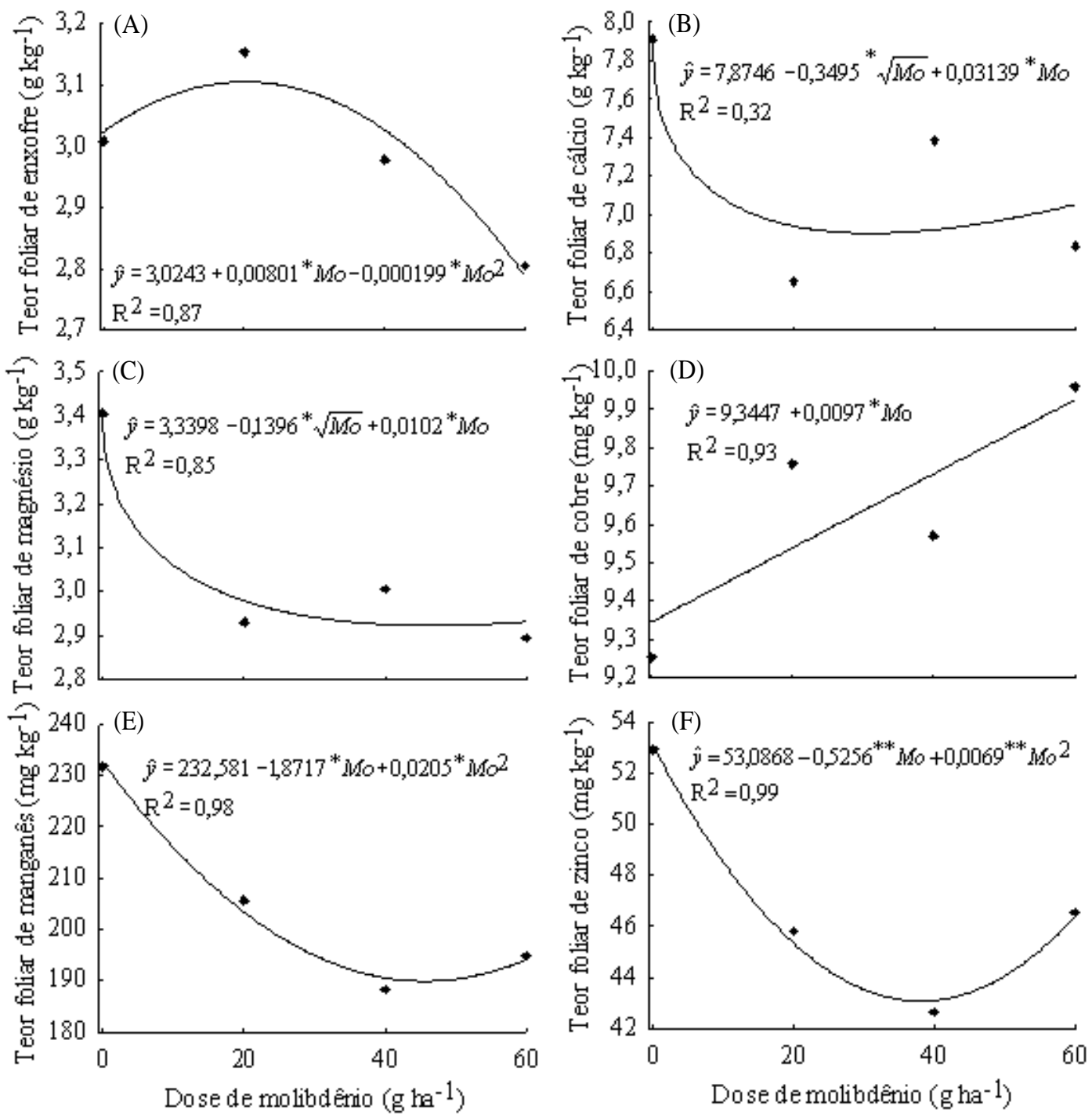

Figura 4 - Efeito das doses de molibdênio nos teores foliares de enxofre (A), cálcio (B), magnésio (C), cobre (D), manganês (E) e zinco (F). Maracaju (MS). UFGD, 2009. 
totalmente a demanda desse micronutriente para se obter elevada eficiência da FBN, ao mesmo tempo em que Milani et al. (2010) verificaram que o método de enriquecimento das sementes não prejudica a qualidade fisiológica das mesmas.

A produtividade da cultura, a massa de cem grãos e o teor de proteína nos grãos de soja foram aumentadas em 62, 22 e $18 \%$, pela adição de 38,33 e $50 \mathrm{~g} \mathrm{ha}^{-1}$ de Mo nas sementes, respectivamente (Figuras 3D, 3E e 3F). Meschede et al. (2004), avaliando o TS e adubação foliar com Co e Mo, observaram que houve um acréscimo de $7 \%$ e $20 \%$ na produtividade, respectivamente, em relação à testemunha sem aplicação de Co e Mo. Campo \& Lantmann (1998) observaram incrementos na produtividade e no teor de proteínas dos grãos da soja com aplicação de até $100 \mathrm{~g} \mathrm{ha}^{-1}$ de Mo via TS. Santos \& Estefanel (1986) avaliaram a utilização de micronutrientes aplicados nas sementes de soja e concluíram que a aplicação de Mo aumentou o rendimento de grãos em condições de maior acidez no solo. Meshede et al. (2004) também encontraram aumento (média de 4\%) no teor de proteínas nos grãos com o uso do Mo via TS.

$\mathrm{O}$ teor foliar de $\mathrm{S}$ sofreu pequeno incremento $(2 \%)$ com a dose de $20 \mathrm{~g} \mathrm{ha}^{-1} \mathrm{de} \mathrm{Mo}$; a partir dessa dose, observouse que os teores foliares de $\mathrm{S}$ diminuíram abaixo dos valores atingidos sem a aplicação de Mo (Figura 4A). Contudo, os teores encontrados estão compreendidos na faixa considerada ideal para a soja (Embrapa, 2008). Os teores foliares de $\mathrm{Ca}, \mathrm{Mg}$, Mn e Zn foram diminuídos em até 12, 14, 18 e $19 \%$, respectivamente, com a aplicação de 31, 47, 46 e $38 \mathrm{~g} \mathrm{ha}^{-1}$ de Mo (Figura 4). Quaggio et al. (1998) avaliaram doses de Mo de até $100 \mathrm{~g} \mathrm{ha}^{-1}$ aplicadas nas sementes de soja e observaram que os teores de $\mathrm{Ca}$ e $\mathrm{Mg}$ diminuíram significativamente; no entanto, os autores consideraram as variações pouco expressivas. A diminuição dos teores dos respectivos nutrientes pode ter resultado de um efeito de diluição dos mesmos no tecido, já que ocorreu um incremento de até $20 \%$ na matéria seca da parte aérea das plantas com a utilização do Mo. Porém, salienta-se que a diminuição dos teores desses nutrientes não foi prejudicial para a cultura, já que apresentaram-se dentro dos limites considerados como ideais para a cultura, com exceção do Zn, que se apresentou como teor alto para a cultura (Embrapa, 2008). O teor foliar de $\mathrm{Cu}$ foi aumentado linearmente em até $7 \%$ quando se adicionou Mo nas sementes; no entanto, em todos os tratamentos, os teores de $\mathrm{Cu}$ se mantiveram em níveis considerados adequados para a cultura da soja (Figura 4C). Esse resultado contraria resultados observados em outros estudos, citados por Olsen (1972), em que a adição de Mo provocou redução no teor foliar de $\mathrm{Cu}$.

A adição de gesso ao solo promoveu alterações significativas $(\mathrm{p}<0,05)$ no teor foliar de $\mathrm{S}$ e $\mathrm{Mg}$, no número de nódulos das plantas e na massa de cem grãos (Figura 5).
Na dose de $1.920 \mathrm{~kg} \mathrm{ha}^{-1}$ de gesso agrícola, observou-se aumento de $8 \%$ nos teores foliares de S (Figura 5A); esse comportamento era esperado, visto que o gesso é fonte de S para as culturas (Caires et al., 1998; Raij, 2008; Soratto \& Crusciol, 2008). Entretanto, o acréscimo no teor foliar de $\mathrm{S}$ não foi linear, provavelmente porque não existe consumo de luxo desse nutriente nas plantas (Malavolta, 2006). Mesmo onde não se utilizou o gesso agrícola, os teores foliares de $\mathrm{S}$ se mantiveram dentro dos valores considerados adequados para a cultura da soja. $\mathrm{O}$ teor foliar de $\mathrm{Mg}$ foi reduzido de forma linear em $10 \%$, com a utilização de doses de até $3.000 \mathrm{~kg} \mathrm{ha}^{-1}$ de gesso (Figura 5B). Resultados semelhantes foram obtidos por Caires et al. (2003), que observaram reduções dos teores foliares de $\mathrm{Mg}$ com aplicação de doses de até $9.000 \mathrm{~kg} \mathrm{ha}^{-1}$ de gesso. No entanto, os teores foliares de $\mathrm{Mg}$ foram considerados adequados para a cultura (Embrapa, 2008). A diminuição dos teores de Mg na folhas, pode ter ocorrido pela provável lixiviação de $\mathrm{Mg}$ no solo devido a utilização do gesso.

O número de nódulos da soja foi aumentado em $10 \%$, na dose estimada de $1.425 \mathrm{~kg} \mathrm{ha}^{-1}$ de gesso (Figura 5C). Por outro lado, o gesso exerceu uma influência negativa, embora pouco expressiva, na massa de cem grãos ( $\mathrm{p}<0,01)$. Nesse caso, foi observada uma redução de $3 \%$ nesta variável, na dose estimada de $1.270 \mathrm{~kg} \mathrm{ha}^{-1}$ (Figura 5D). Entretanto, não foi verificado efeito negativo na produtividade grãos pela utilização do gesso, pois pode ter ocorrido aumento do número de vagens por planta (atributo não avaliado), nas parcelas em que se utilizou o gesso.

A matéria seca de nódulos das plantas de soja e os teores de $\mathrm{P}$ e Fe não foram influenciados significativamente ( $p>0,05)$, em função das diferentes doses de Mo aplicadas via TS e da utilização de gesso agrícola. A massa de nódulos da soja foi de $207 \mathrm{mg} \mathrm{pl}^{-1}$ em média. Os valores médios de $\mathrm{P}$ e $\mathrm{Fe}$ encontrados foram de $3,5 \mathrm{~g} \mathrm{~kg}^{-1}$ e $188 \mathrm{mg} \mathrm{kg}^{-1}$, respectivamente, sendo considerados adequados para a cultura da soja (Embrapa, 2008). Nogueira \& Melo (2003) também não observaram alterações no teor foliar de $\mathrm{P}$ no primeiro ano de cultivo de soja após a aplicação do gesso agrícola. Em outras condições, Caires et al. (2003) observaram aumentos no teor foliar de $\mathrm{P}$, em que se utilizou gesso, em três safras de soja consecutivas. Estes autores atribuíram esse aumento ao fornecimento de $\mathrm{P}$ como impureza contida no gesso, uma vez que o mesmo foi utilizado em altas doses (até $9.000 \mathrm{~kg} \mathrm{ha}^{-1}$ ); entretanto, no presente estudo, foram utilizadas doses de até $3.000 \mathrm{~kg} \mathrm{ha}^{-1}$. Quaggio et al. (1998), trabalhando com doses de até $100 \mathrm{~g} \mathrm{ha}^{-1}$ de Mo nas sementes de soja, também não observaram influência o Mo sobre o teor foliar de Fe. No entanto, Olsen (1972) e Marcondes \& Caires (2005) enfatizam a ocorrência de efeito antagônico entre conteúdo foliar de Fe e adição de Mo. 

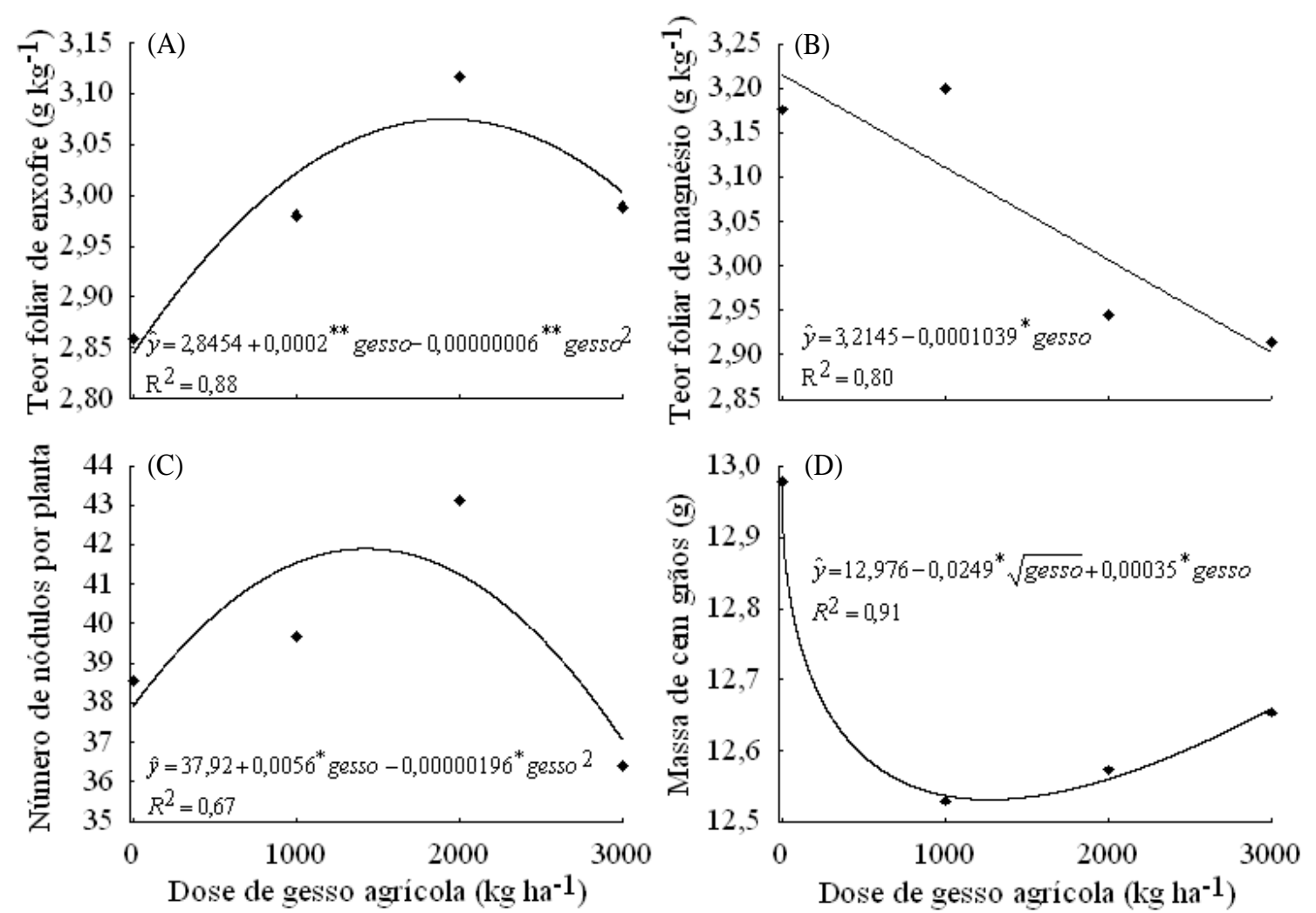

Figura 5 - Efeito das doses de gesso agrícola no teor foliar de enxofre (A), magnésio (B), no número de nódulos por planta (C) e na massa de cem grãos (D). Maracaju (MS). UFGD, 2009.

\section{CONCLUSÕES}

Não houve efeito da interação entre as doses de gesso agrícola e de molibdênio sobre a produtividade e a maioria das características avaliadas na soja.

Quando o teor de S é suficiente para suprir a demanda da cultura, como no solo em estudo, a aplicação de gesso agrícola não demonstra influência no teor foliar de nitrogênio e na produtividade da soja.

O Mo proporciona incrementos na produtividade e no teor de proteínas dos grãos de soja.

\section{REFERÊNCIAS BIBLIOGRÁFICAS}

ALBINO, U.B.; CAMPO, R.J. Efeito de fontes e doses de molibdênio na sobrevivência do Bradyrhizobium e na fixação biológica de nitrogênio em soja. Pesquisa Agropecuária Brasileira, Brasília, v.36, n.3, p.527-534, 2001.

BARNES, J.D.; BALAGUER, L.; MANRIQUE, E.; ELVIRA, S.; DAVISON, A.W. A reappraisal of the use of DMSO for the extraction and determination of chlorophylls a and $\mathrm{b}$ in lichens and higher plants.

Environmental and Experimental Botany, Bronx, v.32, p.85-100, 1992.

CAIRES, E.F.; BLUM, J.; BARTH, G.; GARBUIO, F.G.; KUSMAN, M.T. Alterações químicas do solo e resposta da soja ao calcário e gesso aplicados na implantação do sistema plantio direto. Revista Brasileira de Ciência do Solo, Campinas, v.27, p.275-286, 2003.

CAIRES, E.F.; CHUEIRI, W.A.; MADRUGA, E.F.; FIGUEIREDO, A. Alterações de características químicas do solo e resposta da soja ao calcário e gesso aplicados na superfície em sistema de cultivo sem preparo do solo. Revista Brasileira de Ciência do Solo, Campinas, v.22, p.27-34, 1998.

CAMPO, R.J.; ARAUJO, R.S.; HUNGRIA, M.

Molybdenum-enriched soybean seeds anhance $\mathrm{N}$ accumulation, seed yield, and seed protein content in Brazil. Field Crops Research, Oxford, v.110, p.219-224, 2009. 
CAMPO, R.J.; LANTMANN, A.F. Efeitos de micronutrientes na fixação biológica do nitrogênio e produtividade da soja. Pesquisa Agropecuária Brasileira, Brasília, v.33, n.8, p.1245-1253, ago. 1998.

\section{EMPRESA BRASILEIRA DE PESQUISA}

AGROPECUÁRIA. Correção e manutenção da fertilidade do solo. In: __ Tecnologias de produção de soja: região central do Brasil, 2009 e 2010. Londrina: Embrapa Soja; Embrapa Cerrados; Embrapa Agropecuária Oeste, 2008. 262p. (Sistemas de produção, 13).

FURLANI JUNIOR, E.; NAKAGAWA, J.; BULHÕES, L.J.; MOREIRA, J.A.A.; GRASSI FILHO, H. Correlação entre leituras de clorofila e níveis de nitrogênio aplicados em feijoeiro. Bragantia, Campinas, p.171-175, 1996.

HUNGRIA, M.; CAMPO, R.J.; MENDES, I.C.A importância do processo de fixação biológica do nitrogênio para a cultura da soja: componente essencial para a competitividade do produto brasileiro. Londrina: Embrapa Soja; Embrapa Cerrados, 2007. 80p. (Documentos, 283).

HUNGRIA, M.; CAMPO, R.J.; MENDES, I.C.; GRAHAM, P.H. Contribution of biological nitrogen fixation to the $\mathrm{N}$ nutrition of grain crops in the tropics: the success of soybean (Glycine max (L.) Merr.) in SouthAmerica. In: SINGH, R.P.; SHANKAR, N.; JAIWAL, P.K. (Ed.). Nitrogen nutrition and sustainable plant productivity. Houston: Studium, 2006. p.43-93.

MALAVOLTA, E.; VITTI, G.C.; OLIVEIRA, S.A. Avaliação do estado nutricional das plantas: princípios e aplicações. 2.ed. Piracicaba: Potafos, 1997. 319p.

MALAVOLTA, E. Manual de nutrição mineral de plantas. São Paulo: Agronômica Ceres, 2006. 638p.

MARCONDES, J.A.P.; CAIRES, E.F. Aplicação de molibdênio e cobalto na semente para cultivo da soja. Bragantia, Campinas, v.64, n.4, p.687-694, 2005.

MASCARENHAS, H.A.A.; BRAGA, N.R.; MIRANDA, M.A.C.; TISSELLI-FILHO, O.; MIYASAKA, S. Calagem e adubação da soja. In: A soja no Brasil Central. 3.ed. Campinas: Fundação Cargill, 1986. CD-ROM.
MESCHEDE, D.K.; BRACCINI, A. de L.; BRACCINI, M. do C.L.; SCAPIM, C.A.; SCHUAB, S.R.P. Rendimento, teor de proteínas nas sementes e características agronômicas das plantas de soja em resposta à adubação foliar e ao tratamento de sementes com molibdênio e cobalto. Acta Scientiarum Agronomy, Maringá, v.26, n.2, p.139-145, 2004.

MILANI, G.L.; OLIVEIRA, J.A.; PEREIRA, E. de M.; CARVALHO, B.O.; OLIVEIRA, G.E.; COSTA, R.R. Aplicação foliar de molibdênio durante a maturação de sementes de soja. Ciência e Agrotecnologia, Lavras, v.34, n.4, p.810-816, jul./ago., 2010.

NOGUEIRA, M.A.; MELO, W.J. Enxofre disponível para a soja e atividade de arilsulfatase em solo tratado com gesso agrícola. Revista Brasileira de Ciência do Solo, Campinas, v.27, p.655-663, 2003.

OLSEN, S.R. Micronutrient interactions. In: MORTVEDT, J.J.; GIORDANO, P.M.; LINDSAY, W.L. (Eds.).

Micronutrients in agriculture. Madison: Soil Science Society of America, 1972. p.243-264.

PESSOA, A.C. dos S.; LUCHESE, E.B.; CAVALLET, L.E.; GRIS, E.P. Produtividade de soja em resposta à adubação foliar, tratamento das sementes com molibdenio e inoculação com Bradyfhizobium japonicum. Acta Scientiarum, Maringá, v.21, n.3, p.531-535, 1999.

PROTOCOLO para análise da qualidade e da eficiência agronômica de inoculantes, estirpes e outras tecnologias relacionados ao processo de fixação biológica do nitrogênio em leguminosas. In: REUNIÃO DA REDE DE LABORATÓRIOS PARA RECOMENDAÇÃO, PADRONIZAÇÃO E DIFUSÃO DE TECNOLOGIA DE INOCULANTES MICROBIANOS DE INTERESSE AGRÍCOLA, 13., 2006, Londrina. Anais... Londrina: Embrapa Soja, 2007. p.89-124. (Embrapa Soja. Documentos, 290).

QUAGGIO, J.A.; GALLO, P.B.; FURLANI, A.M.C.; MASCARENHAS, H.A.A. Isoquantas de produtividade de soja e sorgo para níveis de calagem e molibdênio.

Revista Brasileira de Ciência do Solo, Campinas, v.22, p.337-344, 1998.

RAIJ, B. van. Gesso na agricultura. Campinas: Instituto Agronômico, 2008. 233p. 
SANTOS, O.S. dos; ESTEFANEL, V. Efeito de micronutrientes e do enxofre aplicados nas sementes de soja. Revista do Centro de Ciências Rurais, v.16, n.1, p.5-17, 1986.

\section{SECRETARIA DE PLANEJAMENTO E} COORDENAÇÃO GERAL. Atlas multireferencial: Mato Grosso do Sul. Campo Grande: SEPLAN/IBGE, 1990. 27p.

SFREDO, G.J.; BORKERT, C.M.; NEPOMUCENO, A.L.; OLIVEIRA, M.C.N. Eficácia de produtos contendo micronutrientes, aplicados via semente, sobre produtividade e teores de proteína da soja. Revista Brasileira de Ciência do Solo, Campinas, v.21, p.41-45, 1997.

SORATTO, R.P.; CRUSCIOL, C.A.C. Atributos químicos do solo decorrentes da aplicação em superfície de calcário e gesso em sistema plantio direto recémimplantado. Revista Brasileira de Ciência do Solo, Campinas, v.32, p.675-688, 2008.

SOUSA, D.M.G. de; LOBATO, E. Correção da acidez do solo. In: SOUSA, D.M.G. de; LOBATO, E. (Eds.).

Cerrado: correção do solo e adubação. Planaltina: Embrapa Cerrados, 2002. p.81-96.
SOUZA, L.C.F.de; ZANON, G.D.; PEDROSO, F.F.; ANDRADE, L.H.L.de. Teor de proteína e de óleo nos grãos de soja em função do tratamento de sementes e aplicação de micronutrientes. Ciência e Agrotecnologia, Lavras, v.33, n.6, p.1586-1593, nov./dez., 2009.

TANAKA, R.T.; MASCARENHAS, H.A.A.; BULISANI, E.A.; CAMPIDELLI, C.; OTAVIO, S.D. Resposta da soja ao molibdênio aplicado em solo arenoso de cerrado de baixa fertilidade. Pesquisa Agropecuária Brasileira, Brasília, v.28, n.2, p.253-256, fev. 1993.

TEIXEIRA, K.R.S.; MARIN, V.A.; BALDANI, J.I.

Nitrogenase: bioquímica do processo de FBN Seropédica: Embrapa Agrobiologia, 1998. 25p.

(Documentos, 84).

UNIVERSIDADE FEDERAL DE VIÇOSA.SAEG Sistema para Análises Estatísticas. Versão 9.1. Viçosa, MG: Fundação Arthur Bernardes-UFV, 2007.

VARGAS, M.A.T.; HUNGRIA, M. Fixação biológica do nitrogênio na cultura da soja. In: Biologia dos solos dos cerrados. Planaltina: Embrapa-CPAC, 1997. p.295-360. 